\title{
New Approach to Estimating the Standard Deviations of Lognormal Cost Variables in the Monte Carlo Analysis of Construction Risks
}

\author{
Chen-Yu Chang ${ }^{1} \quad$ Jia-Wen $\mathrm{Ko}^{2}$
}

\begin{abstract}
If soundly conducted, risk assessment could yield considerable savings for project investors. Monte Carlo Simulation (MCS) has been widely embraced by risk management guides as an instrumental tool for this purpose. This research aims to develop a new method to improve the rigor of MCS by establishing the link between parameter estimation and assessment of individual risk sources. The method is validated by virtue of its predictive power for the likelihood of a project being successful in securing investors. Eight Taiwanese sewerage Build-Operate-Transfer projects are investigated. Compared to the discounted cash flow approach, this new method can provide a more accurate prediction using the expert's assessment as input of financial impact and occurrence likelihood of individual risks. This finding furnishes solid empirical evidence for the value MCS might add to project appraisal.
\end{abstract}

\section{Keywords:}

Monte Carlo simulation, risk allocation, risk modelling, PPP/ BOT, sewerage system

\footnotetext{
${ }^{1}$ corresponding author, Bartlett School of Construction and Project Management, University College London, 1-19 Torrington Place, London WC1E 7HB. Email: chen-yu.chang@ucl.ac.uk

${ }^{2}$ Bartlett School of Construction and Project Management, University College London, 1-19

Torrington Place, London WC1E 7HB. Email: ko.chiawen@gmail.com
} 


\section{Introduction}

In the management of construction projects, risk management is an area where considerable financial savings could be yielded (Infrastructure Risk Group, 2013). A crucial step of project risk management lies in the assessment of potential risk sources, whereby the optimal responses can be formulated (Project Management Institute, 2008). Monte Carlo Simulation (MCS) has been widely recommended by risk management guides as an effective tool for the analysis of risk impacts (Dailami et al., 1999; HM Treasury, 2007; UNEP, 2007). Rather than relying upon the point estimate, MCS enables a much broader range of uncertain eventualities to be considered in risk analysis (Korn et al., 2010). Despite being instrumental in understanding and predicting the behavior of systems, this simulation method is still criticised by some as being "no better than the assumptions built into it" (p.14) (Simon, 2001). Since MCS requires detailed input data (Aven, 2008), particular attention should be paid to the estimation of statistical parameters of distributions. Unfortunately, in project appraisal, a lack of historical information on risks is more of a norm than an exception. In practice, there are two popular solutions: first, three-point estimates (low bound, most likely and high bound) can be elicited from experts for each risk source and modelled as a triangular distribution (Rodger and Petch, 1999); second, in circumstances where the type of probability distribution is known, experts may be asked to estimate the mean and standard deviation of the distribution directly. The practice of direct estimation is easy to implement, but may attract high measurement errors. This research represents an attempt to improve the rigor of MCS implementation while maintaining its practicality. The central proposition is that measuring individual risk sources can result in more reliable parameter estimation than measuring project risks as a whole. A new method is therefore required to allow the expert's subjective assessment of risk impacts to be 
incorporated into parameter estimation. This is the knowledge gap this research intends to fill.

An important test for the validity of a new approach lies in the accuracy of its prediction (Green, 2002). In this research, the testing point is how well the simulation model can predict a project's likelihood of success in securing investors. A programme of 34 sewerage Build-Operate-Transfer (BOT) projects from Taiwan provides an ideal data source for two reasons: first, these projects all involve substantial capital investment and considerable risks, so the quality of pre-contract risk analysis could fundamentally change the project's financial viability; second, a large proportion of projects failed to secure investors. In the end, eight projects are chosen, half of which experienced failure in tender. A customized questionnaire is designed to collect expert assessment of all potential risk impacts in each project. In contrast to the traditional discounted cash flow (DCF) approach, the new method can produce more accurate predictions for the tender outcome.

\section{Literature review}

In the DCF approach, risk impacts are captured by the discount rate. The deterministic nature of the DCF approach is not adequate to reveal the whole picture of possible economic outcomes in complex projects (Mishra et al., 2012; Ye and Tiong, 2000). Therefore, in practice, MCS is also employed to examine if the appraisal result remains robust in cases where risk realisations deviate from the base scenario (Binkowitz and Wartenberg, 2001; Flanagan and Norman, 1993). This is accomplished by simulating the full system with each risk variable randomly chosen from its probability distribution for hundreds or even thousands of times, as a result producing the outcome in the form of a probability distribution (Kwak and Ingall, 2007). However, MCS has 
not been universally utilized in practice due to the difficulty in choosing probability distributions for risk variables and estimating the parameters required (e.g., mean and standard deviation) (Sonmez, 2004). For the former, practitioners mainly rely on prior understanding of the nature of risk variables. Modelling project cost risk as a lognormal variable is a good example (Smith et al., 2006; Spooner, 1974; Touran and Wiser, 1992). Regarding the latter, when historical data is available, the parameters of a distribution can be obtained through curve fitting (Chou, 2011; Roseberry and Burmaster, 1992). Nonetheless, lack of data is a common constraint in the implementation of MCS. One solution is to randomise risk variables by drawing values from a standard uniform distribution $\mathrm{U}(0,1)$ and using them to build other distributions required in the simulation model (Burmaster and Hull, 1997; Wang et al., 2010; Yang, 2005). Another solution is to draw on subjective assessments in choosing parameters. Triangular distribution is a common choice (Choudhry et al., 2014). The simplicity of this distribution has a downside: it tends to overweight extreme outcomes (e.g. large cost overruns) (Wing Chau, 1995). By contrast, it is often suggested that lognormal distributions fit better to real project cost data (Touran and Wiser, 1992; Wall, 1997). Practically, the main challenge rests with how to obtain reliable parameter estimates from experts. Yet, not all information is suitable to be elicited from experts. In Bayesian statistics, there is a long history of studying how to obtain reliable prior information. A general view is that experts should only be asked to evaluate observable quantities and should not be asked to estimate moments of a distribution (Chaloner, 1996; Kadane and Wolfson, 1998). For ease of information elicitation, a practical solution is to seek the expert's evaluation of bounds on the unknown parameters (Pet-Armacost et al., 1999). However, this practice will unduly restrict the choice of probability distributions to those with fixed bounds (e.g., uniform and triangular distribution). When the 
simulation involves unbounded probability distributions (e.g., lognormal distributions), the focus of information elicitation is shifted to the key parameters that determine the location and shape of the distribution. As a rule, second moments of the distribution (i.e., standard deviation) have a greater influence than first moments (i.e., mean) on the simulation result (Seiler and Alvarez, 1996). As aforementioned, it is not a good practice to ask experts to comment on moments. Consequently, a new method is greatly needed to accommodate project-specific conditions into risk analysis so that MCS can be reliably applied in the evaluation of project viability.

\section{Research Design}

Development of the simulation model

As shown in Figure 1, the simulation model takes five variables as input. Dissimilar from the other four variables (household connection revenue, Operation \& Maintenance (O\&M) revenues, total capital investment cost and O\&M cost), the annual construction repayment (PMT) is a risk free variable because it is fixed by the procuring authority at tender. A sewerage BOT project involves multi-phase construction, which may take place in parallel or sequence. The capital cost of each phase $\left(\right.$ Capex $\left._{\mathrm{i}}\right)$ is calculated in accordance with a pre-determined capital expenditure schedule in year $i$ by the government. The investor will start receiving the repayment in the year immediately after the site work is completed (known as settlement point in the project agreement). The future value of a planned capital expense $\left(\right.$ Capex $\left._{\mathrm{i}}\right)$ in one construction phase at the settlement point $F V_{s p}\left(\right.$ Capex $\left._{i}\right)$ is annualized to form the annual construction repayment for that phase. The summation of annual construction repayments from $p$ different completed phases makes up the "cumulative" annual PMT for any year $\left(P M T_{t}\right)$, i.e., 


$$
\mathrm{PMT}_{t}=\sum_{p}\left\{\sum_{i}^{m} \mathrm{FV}_{\text {sp }}\left(\text { Capex }_{i}\right)\left[\frac{k \times(1+k)^{n-m}}{(1+k)^{n-m}-1}\right]\right\}
$$

where $k$ is the discount rate; $m$ is the pre-specified settlement point year for each construction phase; $n$ is the total duration of the concession contract. $P M T_{t}$ is known to all bidders prior to tender and thus contains no risk. Further technical details of Eq.(1) can be found in Lee et al. (2009).

Second, the payment for household connection is based on the actual amount of wastewater treatment instead of a fixed payment, in order to encourage the private sector to speed up the installation of household connection. For this reason, the household connection installation tariff $(\bar{C})$ is calculated on the basis of total household connection installation cost per unit of estimate wastewater inflow in the concession period.

$$
\bar{C}=\frac{\sum_{i=1}^{n} \frac{C_{i}}{(1+k)^{i}}}{\sum_{i=1}^{n} \frac{Q_{e i}}{(1+k)^{i}}}
$$

where $C_{i}$ is the household connection installation cost in year $i ; Q_{e i}$ is the estimate wastewater inflow in year $i$. The payment that the investor is entitled for its work in household connection installation $\left(\boldsymbol{H} \boldsymbol{T}_{\boldsymbol{i}}\right)$ is linked to the actual volume of wastewater in year $i, \boldsymbol{Q}_{\boldsymbol{a} i}$.

$$
H T_{i}=\bar{C} \times Q_{a i}
$$

Third, the O\&M payment is tied to the fixed $\left(F C_{i}\right)$ and variable O\&M cost $\left(V C_{i}\right)$ involved in the processing of the actual quantity of wastewater. The fixed O\&M annual revenue in year $i\left(F T_{i}\right)$ is the product of the average fixed O\&M tariff $(\overline{F T})$ and the actual volume of water processed. 


$$
\begin{gathered}
\overline{F T}=\frac{\sum_{i=1}^{n} \frac{F C_{i}}{(1+k)^{i}}}{\sum_{i=1}^{n} \frac{Q_{e i}}{(1+k)^{i}}} \\
F T_{i}=\overline{F T} \times Q_{a i}
\end{gathered}
$$

Similarly, the variable O\&M annual revenue in year $i\left(\boldsymbol{V} \boldsymbol{T}_{\boldsymbol{i}}\right)$ is the product of the average variable O\&M tariff $(\overline{\boldsymbol{V} T})$ and the actual volume of water processed.

$$
\begin{aligned}
\overline{V T} & =\frac{\sum_{i=1}^{n} \frac{V C_{i}}{(1+k)^{i}}}{\sum_{i=1}^{n} \frac{Q_{e i}}{(1+k)^{i}}} \\
V T_{i} & =\overline{V T} \times Q_{a i}
\end{aligned}
$$

In both Eq.(5) \& Eq.(7), the risk stems from the volume of water actually processed. In Taiwan, wastewater mainly comes from households with only a small proportion from commercial establishments. Annual water consumption can be modelled as a normal variable and thus so is operating revenue (Ranasinghe, 1999).

Fourth, on the cost side, the most significant risk is associated with capital investment cost. The capital investment consists of three parts: wastewater treatment plant (WWTP), pipeline (PL) and household connection (HC). The distribution of uncertain project cost is mostly skewed to the left; namely, that minor cost shocks are much more likely to occur than major ones. As a result, there is good reason to assume cost-related risks to be a lognormal variable (Ranasinghe, 1999; Touran and Wiser, 1992). This distribution is featured by its mode being less than its mean. As will be demonstrated later, if the mode and mean are known, it is possible to estimate a lognormal distribution's two parameters. The cost estimates reported in the feasibility study can be taken as the modes of cost risk variables because in the current cost estimating practice, project cost is normally made up of the risk-unadjusted cost estimate and a contingency reserve (known as risk allowance) (RICS, 2012a, b). At the feasibility stage, the former is mainly reflective of the most likely cost (i.e., the mode) 
while the latter is set to a level sufficient to buffer average cost overruns. Therefore, the total of cost estimate and risk allowance can be regarded as a proxy of mean cost. To estimate the magnitude of risk allowance more precisely, a questionnaire is designed to elicit expert assessment of the most likely impact and occurrence likelihood of all risk sources in the project, whereby the total expected loss can be worked out as a measure of contingency reserve.

Fifth, the O\&M cost contains both fixed and variable elements. The former indicates the fixed expenses regardless of the volume of wastewater treated (e.g., salary), while the later varies with how much wastewater is treated.

The two revenue and three cost elements are considered in a cash flow model as the basis for evaluating the financial feasibility of projects from the perspective of investors. The output of the model is project NPV (net present value). When NPV is greater than zero, the project is judged to be investible. In Taiwan's sewerage BOT programme, all concessionaires are assumed to have the same capital structure. The cost of capital is evaluated by the weighted average cost of capital (WACC), where WACC $=$ average interest rate $\times$ ratio of debt to total capital $\times(1$-Company Income Tax $)$ + equityholder's required rate of return $\times$ ratio of equity to total capital $=5 \% \times 70 \% \times$ $(1-25 \%)+10 \% \times 30 \%=5.625 \%$. This rate $(5.625 \%)$ is specified in the standard contract.

\section{Questionnaire design and survey}

The questionnaire comes with four sections: (1) project background information, (2) respondent profile, (3) explanation of voting scales against risk impact and likelihood, and (4) respondent's assessment of impact and occurrence likelihood of listed risks. By reference to the feasibility study report of each sewerage BOT project, the main risk types are identified and grouped into three categories (see Table 1): 
general risks (those likely to impact the whole project life cycle), construction risks, operating risks. For each risk group, experts are asked to assign a score to the most likely impact ( 5 bands) and occurrence likelihood (5 bands) in accordance with the scoring system in Table 2 and 3.

Following the practice in Marsh (2007), the simple scoring system of risk impact (Table 2) and occurrence likelihood (Table 3) is translated into the midpoint of the corresponding band. The translations are straightforward, excepting the fifth band of risk impact (financial loss more than $20.1 \%$ of the total construction cost $\left(\boldsymbol{C} \boldsymbol{C}_{\boldsymbol{e}}\right)$ ). This research takes a simplifying assumption to use $20.1 \%$ as its estimate, which means only the lower-bound estimate of this band is considered. As very few responses indicate the risk impact could rise to this extreme, the impact of the assumption on the simulation result could be fairly benign.

With all the estimates, the total expected risk loss of a project can be calculated as follows:

$$
\begin{gathered}
E L=E L_{G}+E L_{C}+E L_{O} \\
E L_{G}=C C_{e} \times\left(\sum_{j=1}^{7} I_{G, j} \times P_{G, j}\right) \\
E L_{C}=C C_{e} \times\left(\sum_{j=1}^{5} I_{C, j} \times P_{C, j}\right) \\
E L_{O}=C C_{e} \times\left(\sum_{j=1}^{3} I_{O, j} \times P_{O, j}\right)
\end{gathered}
$$

where $E L_{G}, E L_{C}$ and $E L_{O}$ are the expected loss of general risks, construction risks and operating risks respectively; $I_{G, j}, I_{C, j}$ and $I_{O, j}$ are the midpoint of the band each score falls into for the financial impact of general, construction and operating risks; $P_{G, j}, P_{C, j}$ and $P_{O, j}$ are the midpoint of the band each score falls into for the occurrence likelihood 
of general, construction and operating risks. The subscript $j$ indicates the individual risk source in each risk category. Multiplied by the (most likely) estimated construction $\operatorname{cost}\left(\boldsymbol{C} \boldsymbol{C}_{\boldsymbol{e}}\right)$, the product of likelihood and impact can be converted into monetary risk impact.

In data collection, this research designs a questionnaire to survey experts who have participated in the appraisal of one of the eight projects under study and have at least 5-years experience in cost estimation or risk assessment. The survey proceeds in two stages: First, through interviews of two experts within the CPAMI (Construction and Planning Agency, Ministry of the Interior), a central government agency in charge of the implementation of all sewerage BOT projects in Taiwan, a pilot study is conducted to check the suitability of voting scales, including the number of bands and the endpoints of each band, so as to ensure that questions are reflective of the real situations (e.g., quantum of risk impacts) and easy to answer. Second, eight experts are approached separately to fill out the questionnaire for each project. To avoid the influence of hindsight, respondents are carefully instructed to answer the questions on the basis of the information and judgment in the stage of feasibility study.

\section{Risk allocation analysis}

Since all procuring authorities in the Taiwanese sewerage sector have followed CPAMI's standard contract closely, examining its clauses can help reveal how risks have been allocated in sewerage BOT projects. Wang and Chou (2003) provide a good classification system for characterising how contract clauses can achieve a different risk allocation result. To make these allocation rules work quantitatively in risk analysis, advice was also sought on the way each rule may change the percentage of risk loss borne by the government (Party A) and the investor (Party B). 
1. Rule 1 (Party A: Party B=100\%:0\%):

The contract clauses explicitly stipulate that the government should take certain risks; or even when the contract is silent on the allocation of certain risks, two parties have consensus that Party A should take the risks.

2. Rule 2 (Party A: Party B=0\%:100\%):

The contract clauses explicitly stipulate that the investor should take certain risks; or even when the contract is silent on the allocation of certain risks, two parties have consensus that Party B should take the risks.

3. Rule 3 (Party A: Party B=50\%:50\%):

The contract clauses do not explicitly stipulate which parties bear the risks, and the actual sharing is worked through negotiations when the downside risks eventuate.

4. Rule 4 (Party A: Party B=60\%:40\%):

When risks materialize, Party A guarantees to assist Party B to achieve desirable results; or Party A retains right to accept it or not. In both cases, the investor is still subject to some risk.

5. Rule 5 (Party A: Party B=40\%:60\%):

In the contract clauses, Party A agrees to provide assistance to Party B for mitigating certain risks but offer no guarantee of success.

The risk-sharing ratios of fifteen risk sources identified in Table 1 between the government and the investor are all determined by these rules in the analysis.

\section{Estimation of model parameters}

In the simulation model, risks may arise on both the cost and revenue side. Subject to the impact of both general risks and construction risks, the expected construction cost $(\boldsymbol{E C C})$ comprises the potential loss borne by the investor (bracket in 
Eq.(12)) on top of the most likely cost estimate $\left(\boldsymbol{C} \boldsymbol{C}_{\boldsymbol{e}}\right)$ obtained from the feasibility study report.

$$
E C C=C C_{e}+\left(E L_{G} \times T_{G}+E L_{C} \times T_{C}\right)
$$

where $T_{G}$ and $T_{C}$ represent the percentage of general risks and construction risk transferred to the investor respectively. The expected value of operating cost $(\boldsymbol{E O O C})$ can be expressed similarly:

$$
E O C=O C_{e}+\left(E L_{G} \times T_{G}+E L_{O 1} \times T_{O 1}\right)
$$

Just as $\boldsymbol{C} \boldsymbol{C}_{\boldsymbol{e}}, \boldsymbol{O} \boldsymbol{C}_{\boldsymbol{e}}$ is an estimate of the most likely operating cost from the feasibility study report, which is under the impact of general risks and operating risks. ELOI denotes the expected loss from operating risks exclusive of operating revenue risk $(\mathrm{O}-$ 1, O-2) and $T_{O 1}$ the percentage of operating risks (excluding operating revenue risk) transferred to the investor.

As noted previously, the mode of a lognormal cost variable is based on the estimates in the feasibility study report and the mean from Eq.(12) or Eq.(13). The mean and mode of a lognormal variable are the function of two parameters $(\mu, \sigma)$ :

$$
\begin{aligned}
& \text { Mean }=e^{\mu+\frac{\sigma^{2}}{2}} \\
& \text { Mode }=e^{\mu-\sigma^{2}}
\end{aligned}
$$

Take natural logarithm on both sides of the questions and solve them as a simultaneous equation:

$$
\begin{aligned}
& \sigma=\sqrt{\frac{2}{3}[\operatorname{Ln}(\text { Mean })-\operatorname{Ln}(\text { Mode })]} \\
& \mu=\frac{1}{3}[2 \times \operatorname{Ln}(\text { Mean })+\operatorname{Ln}(\text { Mode })]
\end{aligned}
$$


where $\mu$ and $\sigma$ can be the mean and standard deviation of the natural logarithm of either construction cost or operating cost. With both parameters known, the standard deviation (SD) of the construction cost or operating cost can be easily calculated:

$$
S D=e^{\mu+\frac{1}{2} \sigma^{2}} \sqrt{e^{\sigma^{2}}-1}
$$

Eqs. 12-13 and Eqs. 16-18 jointly build the crucial link needed for accommodating expert assessment into the estimation of lognormal parameters.

On the revenue side, the expected O\&M revenue $(E O R)$ is equal to the most likely revenue estimate $\left(\boldsymbol{O} \boldsymbol{R}_{\boldsymbol{e}}\right)$ minus the impact from operating risks

$$
E O R=O R_{e}-E L_{O 2} \times T_{O P 2}
$$

where $E L_{O 2}$ indicates the expected loss from operating revenue risk $\mathrm{O}-3$ and $T_{O P 2}$ the percentage of operating revenue risk transferred to the investor.

The second revenue source is from household connection (EHT), equal to the estimated household connection revenue $\left(\boldsymbol{H} \boldsymbol{T}_{\boldsymbol{e}}\right)$ minus the same risk impact as EOR.

$$
E H T=H T_{e}-E L_{O 2} \times T_{O P 2}
$$

Regarding the operating revenue risk, the source of variation lies in uncertainty over the quantity of wastewater treated every year, which in turn depends upon the level of water consumption. Taiwan's yearly water consumption per capita $\left(x_{i}\right)$ is available for the period 1975-2004. Relative to the average water consumption per capita over the period $\left(\mu_{c}\right)$, the standard deviation of water consumption $\left(\sigma_{R}\right)$ can be calculated as

$$
\sigma_{R}=\sqrt{\frac{1}{N} \sum_{i=1}^{N}\left(x_{i}-\mu_{c}\right)^{2}}
$$

where $N$ is the number of years between 1975 and 2004. It is assumed that the degree of variation in water consumption will remain stable over the concession period of eight projects. 


\section{Result}

Table 4 reports a comparison of the results from the traditional DCF model and the MCS using this study's new method. According to the former, all of the eight projects turn out to be feasible with a positive net present value and thus should have no problem securing an investor. It is evident that this finding goes against the fact that only four of the projects succeeded, so the traditional appraisal technique fails to effectively differentiate the financial viability of a project.

By contrast, the simulation model can produce the whole NPV distribution on the basis of 5,000 iterations using @Risk. Consideration of risk impacts has made marked changes to the appraisal result: Luo Dong (LD), ZhuNa-TouFen (ZT) and Zhong Li (ZL) are all judged to be investible with a confidence level of over $95 \%$ (i.e., 5th percentile value of NPV is larger than 0). An exception is Bu Ding (BD) where the confidence level is only about $80 \%$. There are two ways to reconcile this finding with the success of the project in securing investment: it may be ascribed to an imprudent investment decision or it may simply indicate the market's tolerance for risk is as low as $80 \%$.

Apart from GangShan-QiaoTou (GQ), none of the three failure projects appear investable in terms of the mean NPV values. When probing further, one finds that the level of confidence at which GQ is financially viable is only $55 \%$ and hence it can comfortably be determined not investible. This result illustrates that better judgement can be achieved through applying the new method.

\section{Limitations}

In the application of MCS in project risk analysis, the effect of correlated input variables may affect simulation results. In this research, all risk sources are assumed to be independent for two reasons: First, in contrast to literature (Chau, 1995; Touran and 
Wiser, 1992), this research follows current cost estimating practices to model project cost as the sum of base cost and risk allowance. The occurrence likelihood and impact of different risk sources appear not as strongly correlated. If that is the case, dependencies can then be safely disregarded (Smith et al., 1992). This assertion needs further scrutiny in the future. Second, the information required for correlation analysis is particularly demanding (Touran and Wiser, 1992), so the error involved in the measurement of correlation coefficients may offset its benefit. However, along with the applications of building information modelling, cost data will be more systematically recorded and that can produce more reliable statistical relationships in the future (Chang, 2015).

\section{Conclusions and suggestions}

The benefit of MCS in improving the quality of project risk assessment is well acknowledged in guidebooks (e.g., HM Treasury's Green Book), but its application is often held back by lack of reliable estimates for the parameters of risk distributions. It becomes particularly challenging when probability distributions are unbounded. To model construction cost as a lognormal cost variable in MCS, the current research develops a simple practical method that enables the variable's standard deviation to be estimated reliably using the data collected from a customised questionnaire, and scrutinizes the validity of the method by testing its ability to predict the odd of success in securing investors in eight Taiwanese sewerage BOT projects (four successes and four failures). The result proves that the new method has a better predictive power than the DCF approach in differentiating project financial viability and that can lend support to make MCS a mandatory appraisal exercise in public procurement. 


\section{References}

Aven, T., 2008. Risk analysis: assessing uncertainties beyond expected values and probabilities. John Wiley \& Sons, New Jersey.

Binkowitz, B.S., Wartenberg, D., 2001. Disparity in quantitative risk assessment: A review of input distributions. Risk Analysis, 21(1),75-90.

Burmaster, D.E., Hull, D.A., 1997. Using lognormal distributions and lognormal probability plots in probabilistic risk assessments. Human and Ecological Risk Assessment, 3(2),235-255. Chaloner, K., 1996. Elicitation of prior distributions, in: Berry, D., Stangl, D. (Eds.), Case Studies in Bayesian Biostatistics. Dekker, New York, pp. 141-156.

Chang, C., 2015. Risk-bearing capacity as a new dimension to the analysis of project governance. International Journal of Project Management, 33(6),1195-1205.

Chau, K., 1995. Monte Carlo simulation of construction costs using subjective data. Construction Management and Economics, 13(5),369-383.

Chou, J.-S., 2011. Cost simulation in an item-based project involving construction engineering and management. International Journal of Project Management, 29(6),706-717. Choudhry, R.M., Aslam, M.A., Hinze, J.W., Arain, F.M., 2014. Cost and Schedule Risk Analysis of Bridge Construction in Pakistan: Establishing Risk Guidelines. Journal of Construction Engineering and Management, 140(7),04014020.

Dailami, M., Lipkovich, I., Van Dyck, J., 1999. INFRISK: A Computer Simulation Approach to Risk Management in Infrastructure Project Finance Transactions. The World Bank, Washington DC.

Flanagan, R., Norman, G., 1993. Risk management and construction. Blackwell Scientific Oxford.

Green, K.C., 2002. Forecasting decisions in conflict situations: A comparison of game theory, role-playing, and unaided judgement. International journal of forecasting, 18(3),321-344.

HM Treasury, 2007. The Green Book - Appraisal and Evaluation in Central Government. TSO, London.

Infrastructure Risk Group, 2013. Managing Cost Risk \& Uncertainty in Infrastructure Projects. Infrastructure Risk Group and Insitute of Risk Management, London Kadane, J., Wolfson, L.J., 1998. Experiences in elicitation. Journal of the Royal Statistical Society: Series D (The Statistician), 47(1),3-19.

Korn, R., Korn, E., Kroisandt, G., 2010. Monte Carlo methods and models in economics and finance. CRC Press, London.

Kwak, Y.H., Ingall, L., 2007. Exploring Monte Carlo simulation applications for project management. Risk Management, 9(1),44-57.

Lee, C.H., Yu, Y.H., Liu, H.L., 2009. Private participation mechanisms of sewerage BOT project in Taiwan. Journal of Environmental Engineering and Management, 19(6),371-378. Marsh, 2007. Assessment of financial risk management instruments for renewable energy projects-UNEP working group 1 study report. Marsh.

Mishra, S., Khasnabis, S., Dhingra, S.L., 2012. A simulation approach for estimating value at risk in transportation infrastructure investment decisions. Research in Transportation Economics.

Pet-Armacost, J.J., Sepulveda, J., Sakude, M., 1999. Monte Carlo sensitivity analysis of unknown parameters in hazardous materials transportation risk assessment. Risk Analysis, 19(6),1173-1184.

Project Management Institute, 2008. A Guide to the Project Management Body of Knowledge: $\mathrm{PMBOK}^{\circledR}$ Guide. Project Management Institute.

Ranasinghe, M., 1999. Private sector participation in infrastructure projects: a methodology to analyse viability of BOT. Construction Management \& Economics, 17(5),613-623. 
RICS, 2012a. NRM 1 - Order of Cost Estimating and Cost Planning for Capital Building Works. Royal Institute of Chartered Surveyors, London.

RICS, 2012b. NRM 2 - Detailed Measurement for Building Works Royal Institute of Chartered Surveyors, London.

Rodger, C., Petch, J., 1999. Uncertainty \& Risk Analysis. PriceWaterhouseCoopers, London Roseberry, A.M., Burmaster, D.E., 1992. Lognormal distributions for water intake by children and adults. Risk Analysis, 12(1),99-104.

Seiler, F.A., Alvarez, J.L., 1996. On the selection of distributions for stochastic variables. Risk Analysis, 16(1),5-18.

Simon, H.A., 2001. The Science of the Artificial, 3rd Edition ed. MIT Press.

Smith, A.E., Ryan, P.B., Evans, J.S., 1992. The effect of neglecting correlations when propagating uncertainty and estimating the population distribution of risk. Risk Analysis, 12(4),467-474.

Smith, N.J., Merna, T., Jobling, P., 2006. Managing risk in construction projects. Blackwell Pub.

Sonmez, R., 2004. Selection of a probability distribution function for construction cost estimation, 20th Annual ARCOM Conference, Edinburgh.

Spooner, J.E., 1974. Probabilistic estimating. Journal of the Construction Division, 100(1),65-

77.

Touran, A., Wiser, E.P., 1992. Monte Carlo Technique with Correlated Random Variables. Journal of Construction Engineering and Management, 118(2),258-272.

UNEP, 2007. Assessment of Financial Risk Management Instruments For Renewable Energy Projects., Working Group 1 Study Report. United Nations Energy Program, New York.

Wall, D.M., 1997. Distributions and correlations in Monte Carlo simulation. Construction Management \& Economics, 15(3),241-258.

Wang, F., Machemehl, R.B., Popova, E., 2010. Toward monte carlo simulation-based mechanistic-empirical prediction of asphalt pavement performance. Journal of Transportation Engineering, 136(7),678-688.

Wang, M.T., Chou, H.Y., 2003. Risk allocation and risk handling of highway projects in Taiwan. Journal of management in Engineering, 19(2),60-68.

Wing Chau, K., 1995. The validity of the triangular distribution assumption in Monte Carlo simulation of construction costs: empirical evidence from Hong Kong. Construction Management and Economics, 13(1),15-21.

Yang, I.-T., 2005. Simulation-based estimation for correlated cost elements. International Journal of Project Management, 23(4),275-282.

Ye, S., Tiong, R.L.K., 2000. NPV-at-Risk method in infrastructure project investment evaluation. Journal of Construction Engineering and Management, 126(3),227-233. 


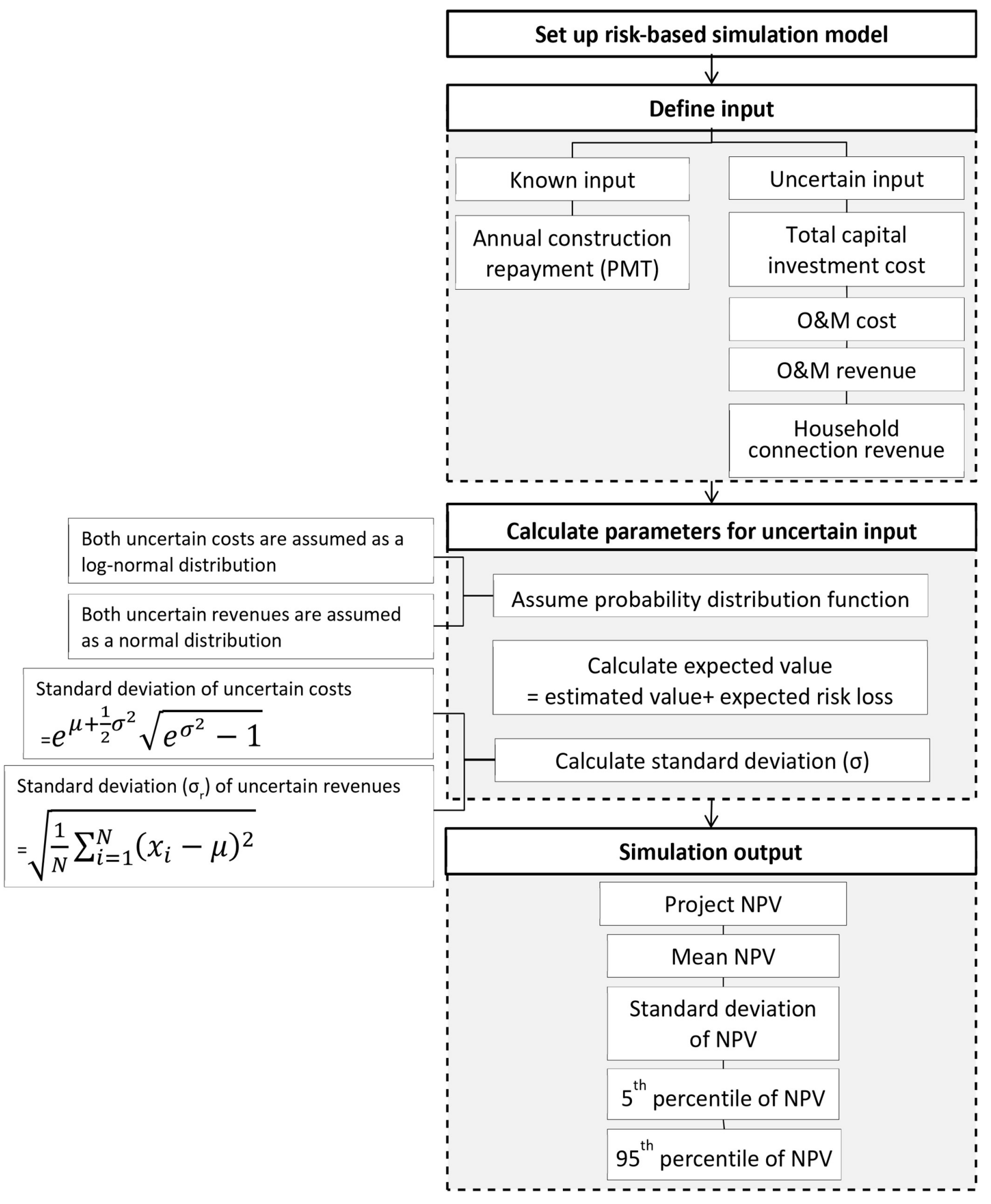


Table 1 Risk Sources Considered in the Analysis

\begin{tabular}{|c|c|c|c|}
\hline Risk category & Code & Risk type & Description \\
\hline \multirow[t]{7}{*}{ General risk } & G-01 & Policy/law risks & $\begin{array}{l}\text { Change in tariff policy/ Change in law/ Tax } \\
\text { increases/ Change in project policy/ Delay in } \\
\text { government payment }\end{array}$ \\
\hline & G-02 & Environmental risks & $\begin{array}{l}\text { Environmental damage/ Change in environmental } \\
\text { standard }\end{array}$ \\
\hline & G-03 & Financial risks & Interest rate / Exchange rate/ Inflation \\
\hline & G-04 & Market risks & $\begin{array}{l}\text { Overestimation in demand / Insufficient revenue } \\
\text { from affiliated facilities }\end{array}$ \\
\hline & G-05 & Labour-related risks & Investor-labour disputes \\
\hline & G-06 & Project financial risks & $\begin{array}{l}\text { Availability of finance / Insolvency of } \\
\text { concessionaire }\end{array}$ \\
\hline & G-07 & Force majeure risks & Natural disaster or war \\
\hline \multirow[t]{5}{*}{$\begin{array}{l}\text { Construction } \\
\text { risk }\end{array}$} & C-01 & Site acquisition risk & $\begin{array}{l}\text { Delay in acquiring wastewater treatment plant site / } \\
\text { Delay in acquiring connection road land/ Delay in } \\
\text { securing pipeline land use permit }\end{array}$ \\
\hline & $\mathrm{C}-02$ & $\begin{array}{l}\text { Construction completion } \\
\text { risk }\end{array}$ & $\begin{array}{l}\text { Delay in schedule/ Design change by government/ } \\
\text { Design change by concession company }\end{array}$ \\
\hline & $\mathrm{C}-03$ & $\begin{array}{l}\text { Construction cost overrun } \\
\text { risk }\end{array}$ & Construction cost overrun \\
\hline & $\mathrm{C}-04$ & Ground condition risk & $\begin{array}{l}\text { Running into geological and historical objects in the } \\
\text { construction process }\end{array}$ \\
\hline & $\mathrm{C}-05$ & Reallocation risk & $\begin{array}{l}\text { Delay in dismantling illegal buildings on site by } \\
\text { government/ Public protest/ Delay in reallocating } \\
\text { other existing pipes }\end{array}$ \\
\hline \multirow[t]{3}{*}{ Operating risk } & $\mathrm{O}-01$ & $\begin{array}{l}\text { Operational performance } \\
\text { risk }\end{array}$ & Concession company lack of management ability \\
\hline & $\mathrm{O}-02$ & Contract termination risk & Project termination due to government policy \\
\hline & $\mathrm{O}-03$ & Operating revenue risk & $\begin{array}{l}\text { Overestimation in population growth rate or water } \\
\text { consumption }\end{array}$ \\
\hline
\end{tabular}


Table 2 Voting scales for risk impact

\begin{tabular}{llll}
\hline Score & Qualitative impact & Impact scale & Description of risk impact scale \\
\hline 1 & Negligible & $<5 \%$ & Financial loss is less than 5\% of total construction cost \\
2 & Minimal & $5.1 \%-10.0 \%$ & Financial loss is between $5.1 \%$ to $10.0 \%$ of total construction cost \\
3 & Significant & $10.1-15.0 \%$ & $\begin{array}{l}\text { Financial loss is between } 10.1 \% \text { to } 15.0 \% \text { of total construction } \\
\text { cost }\end{array}$ \\
& Major & $15.1 \%-20.0 \%$ & $\begin{array}{l}\text { Financial loss is between } 15.1 \% \text { to } 20.0 \% \text { of total construction } \\
\text { cost }\end{array}$ \\
& Catastrophic & $>20.1 \%$ & Financial loss is more than $20.1 \%$ of total construction cost \\
\hline
\end{tabular}


Table 3 Voting scales for occurrence likelihood

\begin{tabular}{llll}
\hline Score & Qualitative likelihood & Probability of occurrence & Description of risk likelihood scale \\
\hline 1 & Very unlikely & $2 \%-5 \%$ & Occurrence once in every 20 to 50 years \\
2 & Unlikely & $5 \%-10 \%$ & Occurrence once in every 10 to 20 years \\
3 & Possible & $10-20 \%$ & Occurrence once in every 5 to 10 years \\
4 & Probably & $20-50 \%$ & Occurrence once in every 2 to 5 years \\
5 & Very likely & $50 \%-100 \%$ & Occurrence once in every 1 to 2 years \\
\hline
\end{tabular}


Table 4 Comparison of predictive power (DCF v.s. MCS)

\begin{tabular}{|c|c|c|c|c|c|c|c|c|c|}
\hline \multirow[b]{2}{*}{ Method } & \multirow[b]{2}{*}{ Statistics } & \multicolumn{4}{|c|}{ Successfully tendered Projects } & \multicolumn{4}{|c|}{ Unsuccessfully tendered Projects } \\
\hline & & $\begin{array}{l}\text { Luo } \\
\text { Dong } \\
\text { (LD) } \\
\end{array}$ & $\begin{array}{c}\text { ZhuNa- } \\
\text { TouFen } \\
(\mathrm{ZT})\end{array}$ & $\begin{array}{c}\mathrm{Bu} \\
\text { Ding } \\
(\mathrm{BD}) \\
\end{array}$ & $\begin{array}{c}\text { Zhong } \\
\text { Li } \\
(\mathrm{ZL})\end{array}$ & $\begin{array}{l}\text { Feng } \\
\text { Yuan } \\
(\mathrm{FY}) \\
\end{array}$ & $\begin{array}{l}\text { Gui } \\
\text { Ren } \\
(\mathrm{GR})\end{array}$ & $\begin{array}{l}\text { Yong } \\
\text { Kang } \\
(\mathrm{YK})\end{array}$ & $\begin{array}{c}\text { GangShan } \\
\text {-QiaoTou } \\
\text { (GQ) }\end{array}$ \\
\hline DCF & mean & 19,024 & 17,606 & 7,526 & 97,057 & 15,113 & 5,124 & 24,122 & 18,079 \\
\hline \multirow{4}{*}{ MCS } & mean & 10,302 & 10,202 & 2,815 & 79,788 & $-6,649$ & $-1,809$ & $-14,789$ & 281 \\
\hline & $5^{\text {th }}$ percentile & 1,906 & 1,886 & $-3,321$ & 56,166 & $-20,714$ & $-7,998$ & $-47,593$ & $-12,496$ \\
\hline & $95^{\text {th }}$ percentile & 17,937 & 17,980 & 8,429 & 102,133 & 6,006 & 3,512 & 13,543 & 11,313 \\
\hline & standard deviation & 4,847 & 4,899 & 3,583 & 14,075 & 8,012 & 3,572 & 18,663 & 7,348 \\
\hline
\end{tabular}

Note: All figures are in present value terms and in thousands New Taiwan Dollars. 